\title{
PROFIL KROMATOGRAFI SENYAWA AKTIF ANTIOKSIDAN DAN ANTIBAKTERI FRAKSI N-HEKSANA DAUN LIBO (FICUS VARIEGATA BLUME)
}

\author{
Rolan Rusli*, Myra Puspha Hardina, Fairul Muflihah, Agung Rahmadani \\ Laboratorium Penelitian dan Pengembangan FARMAKA TROPIS Fakultas Farmasi \\ Universitas Mulawarman, Samarinda, Kalimantan Timur \\ *email: rolan@farmasi.unmul.ac.id
}

\begin{abstract}
Research about chromatographic profile of antioxidant and antibacterial compounds in nhexane fraction of Libo leaves (Ficus variegata Blume.) has been done in order to know the form of chromatographic profile of antioxidant and antibacterial compounds in n-hexane fraction of Libo leaves. Extraction was done by maceration using methanol. Isolation was done by 2 methods, vacuum liquid chromatography (VLC) then followed by conventional column chromatography. Eluent used are n-hexane-ethyl acetate and methanol-chloroform. The results based on conventional column chromatography are as many as 10 fractions. The fractions are being conducted then by a qualitative testing of the antioxidant activity using DPPH method and antibacterial activity test using bioautography TLC method. The results formed as a chromatographic profile of fraction that contain antioxidant and antibacterial activity, which are as many as 5 fractions (NHB1, NHB3, NHB4, NHC1, NHC3) active as an antioxidant and 4 fractions (NHB1, NHC1, NHC2, NHC3) which are active as an antibacterial. The secondary metabolite contents of the fractions are alkaloid, flavonoid and steroid/terpenoid.
\end{abstract}

Key Words: n-hexane fraction of Libo leaves (Ficus variegata Blume.), chromatography, antioxidant, antibacterial

\begin{abstract}
ABSTRAK
Penelitian mengenai profil kromatografi senyawa antioksidan dan antibakteri dalam fraksi $n$ heksana dari daun Libo (Ficus variegata Blume.) telah dilakukan dengan tujuan untuk mengetahui profil kromatografi senyawa antioksidan dan antibakteri dalam fraksi $n$-heksana dari daun Libo. Ekstraksi dilakukan secara maserasi dengan menggunakan pelarut metanol. Isolasi dilakukan dengan 2 metode, kromatografi kolom vakum (KCV) kemudian dilanjutkan dengan kromatografi kolom konvensional (KK). Eluen yang digunakan yaitu $n$-heksan-etil asetat dan metanol-kloroform. Hasil pemisahan yang diperoleh berdasarkan kromatografi kolom konvensional yaitu sebanyak 10 fraksi. Fraksi-fraksi tersebut kemudian dilakukan pengujian aktivitas antioksidan secara kualitatif menggunakan metode DPPH serta pengujian aktivitas antibakteri menggunakan metode KLT bioautografi. Hasil penelitian yang diperoleh berupa profil kromatografi fraksi yang memiliki aktivitas antioksidan dan antibakteri, yaitu sebanyak 5 fraksi (NHB1, NHB3, NHB4, NHC1, NHC3) aktif sebagai antioksidan dan 4
\end{abstract}


fraksi (NHB1, NHC1, NHC2, NHC3) aktif sebagai antibakteri. Kandungan metabolit sekunder dari fraksi-fraksi aktif tersebut antara lain alkaloid, flavonoid dan steroid/terpenoid.

Kata Kunci: fraksi $n$-heksana daun Libo (Ficus variegata Blume.), kromatografi, antioksidan, antibakteri, metabolit sekunder

\section{PENDAHULUAN}

Keanekaragaman hayati tumbuhan Indonesia telah banyak yang diketahui memiliki khasiat pengobatan. Khasiat pengobatan tersebut muncul akibat adanya kandungan senyawa aktif berpotensi dalam tumbuhan tersebut. Beberapa contoh potensi senyawa aktif yaitu sebagai antioksidan dan antibakteri. Antioksidan merupakan senyawa yang berguna untuk menstabilkan radikal bebas [1]. Radikal bebas ialah suatu molekul yang memiliki jumlah elektron ganjil atau elektron tak berpasangan pada lingkaran luarnya. Elektron tak berpasangan tersebut menyebabkan instabilitas sehingga bersifat reaktif. Oleh karenanya untuk mencapai kestabilan, radikal bebas berusaha untuk berikatan dengan senyawa lain yang pada akhirnya menciptakan radikal bebas yang lain [2]. Sedangkan antibakteri suatu zat yang dapat mencegah pertumbuhan dan reproduksi dari bakteri [3]

Libo (Ficus variegata Blume.) merupakan tumbuhan liar yang belum banyak dikenal dan pengetahuan akan manfaatnya juga masih sangat minim. Rijai [4] menyebutkan beberapa potensi buah Libo yaitu sebagai sumber bahan larvasida untuk Aedes aegepti, sitotoksik (antikanker), antioksidan dan antibakteri. Sedangkan pengetahuan mengenai potensi daun Libo masih sangat kurang. Oleh karena itu dilakukan penelitian mengenai potensi senyawa aktif yang terdapat pada daun Libo, khususnya potensi senyawa aktif antioksidan dan antibakteri pada fraksi $n$-heksana. Diduga selain buahnya, daun Libo juga memiliki potensi aktivitas yang tak jauh berbeda.

\section{METODE PENELITIAN}

\section{Alat dan Bahan}

Alat yang digunakan yaitu peralatan kromatografi lapis tipis (KLT), peralatan kromatografi kolom cair vakum (KCV), peralatan kromatografi kolom konvensional (KK), lampu UV 254 \& 366 $\mathrm{nm}$, rotary evaporator, alat-alat kaca dan non kaca. Bahan yaitu daun tumbuhan Libo, silika gel GF 60, metanol, n-heksan, etil asetat, kloroform, aquades, DPPH (Sigma Aldrich), medium NA (Nutrient Agar) (Merck), bakteri Staphylococcus aureus dan Eschericia coli, $\mathrm{HCl}$, pereaksi Dragendorff, pereaksi Mayer, serbuk $\mathrm{Mg}$, $\mathrm{CH}_{3} \mathrm{COOH}$ anhidrat, $\mathrm{H}_{2} \mathrm{SO}_{4}, \mathrm{FeCl}_{3}$.

\section{Prosedur Kerja}

Sampel daun Libo (Ficus variegata Blume.) dibuat menjadi simplisia kemudian diektraksi dengan metanol selama 3 hari pada suhu kamar. Ekstrak kasar metanol difraksinasi dengan $\underline{n}$ heksana sehingga diperoleh ekstrak fraksi $n$-heksana. Ekstrak fraksi $n$-heksana selanjutnya dipisahkan dengan menggunakan metode kromatografi kolom cair vakum (KCV) menggunakan silika gel. Eluen yang digunakan antara lain $n$ heksana:etil asetat dan metanol:kloroform dengan berbagai macam perbandingan. Fraksi yang diperoleh kemudian dilanjutkan pemisahan dengan metode kolom konvensional (KK). Hasil pemisahan dilakukan pengujian aktivitas antioksidan dan antibakteri. Pengujian antioksidan menggunakan metode penyemprotan DPPH. DPPH dibuat dalam konsentrasi $80 \mathrm{ppm}$. Pengujian antibakteri 
menggunakan metode kromatografi lapis tipis (KLT) bioautografi. Bakteri uji yang digunakan yaitu Staphylococcus aureus dan Escherichia coli. Fraksi yang memiliki aktivitas baik antioksidan dan antibakteri dilakukan pengujian metabolit sekunder.

\section{HASIL DAN PEMBAHASAN}

Ekstraksi simplisia daun Libo (Ficus variegata Blume.) kering sebanyak 2271,5 gram menggunakan 5 L metanol menghasilkan ekstrak kasar sebanyak 210,77 gram. Maserasi merupakan metode ekstraksi cara dingin yang sederhana dan tepat untuk digunakan pada simplisia daun. Metanol dipilih karena sifat kepolarannya yang dapat melarutkan baik senyawa polar maupun non polar. Ekstrak kasar sebanyak
50,29 gram difraksinasi menggunakan $n$ heksana menghasilkan ekstrak fraksi $n$ heksana kering sebanyak 11,255 gram.

Fraksi $n$-heksana tersebut kemudian dipisahkan menggunakan kromatografi kolom cair vakum (KCV) menghasilkan 14 fraksi yang dikelompokkan menjadi 4 kelompok fraksi besar yaitu NHA, NHB, NHC dan NHD (Gambar 1 dan 2). Eluen yang digunakan yaitu $n$-heksana:etil asetat dengan perbandingan $9: 1 ; 8,5: 1,5 ; 8: 2$; $7,5: 2,5 ; \quad 7: 3 ; \quad 6: 4 ; \quad 1: 1 \quad$ dan kloroform:methanol dengan perbandingan $9: 1 ; 8: 2 ; 7: 3 ; 6: 4 ; 1: 1 ; 4: 6$ yang masingmasing dibuat dalam $400 \mathrm{~mL}$. Pengelompokkan fraksi dilakukan berdasarkan kesamaan noda hasil elusi menggunakan metode KLT.

(1)

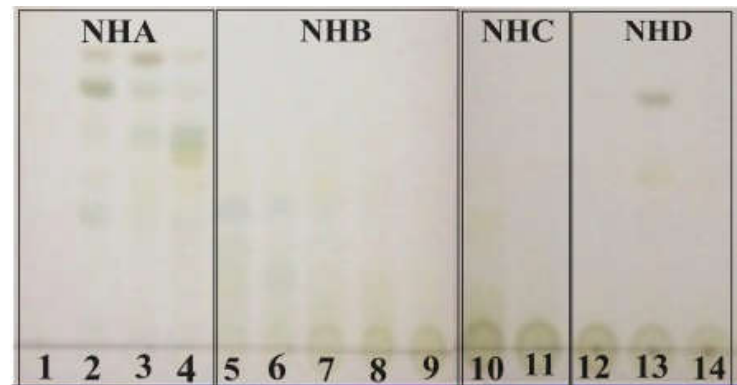

(2)

(3)

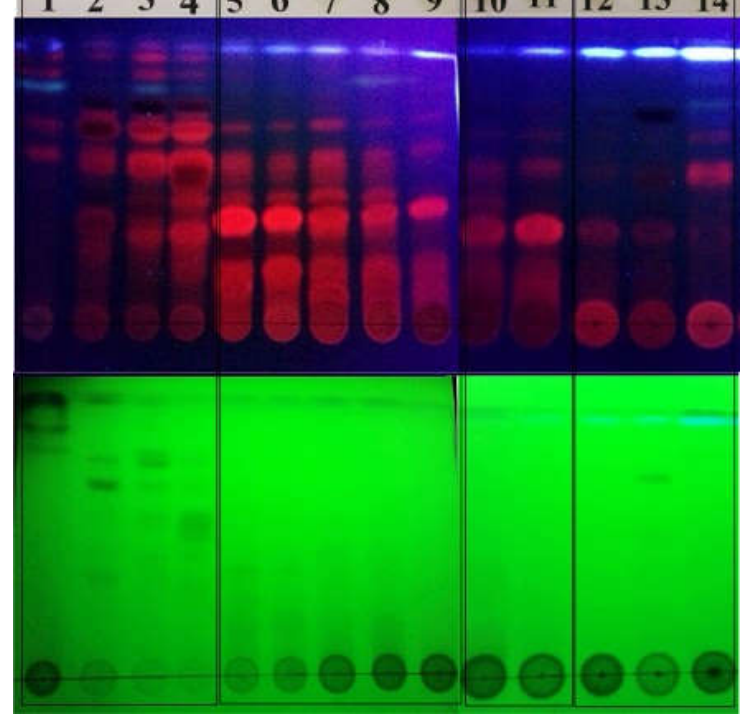

Gambar 1. Hasil fraksinasi metode KCV sebanyak 14 fraksi yang dikelompokkan menjadi 4 kelompok besar dengan eluen $n$-heksana:etil asetat (8:2) diamati pada (1) sinar tampak, (2) sinar UV 254 nm, dan (3) 366 nm 


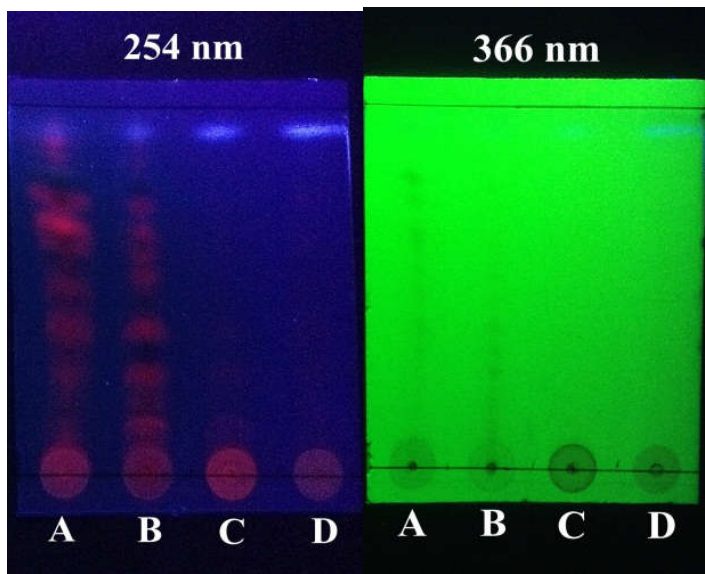

Gambar 2. Hasil KLT 4 kelompok besar (A)NHA, (B)NHB, (C)NHC, (D)NHD menggunakan eluen $n$-heksana:etil (8:2) diamati pada sinar UV $254 \mathrm{~nm}$, dan $366 \mathrm{~nm}$

Pemisahan dilanjutkan dengan menggunakan metode kromatografi kolom konvensional. Fraksi yang dipisahkan yaitu NHB dan NHC, sedangkan Fraksi NHA dan NHD memiliki berat yang terlalu sedikit untuk dilakukan pemisahan sehingga sulit untuk dilakukan pemisahan

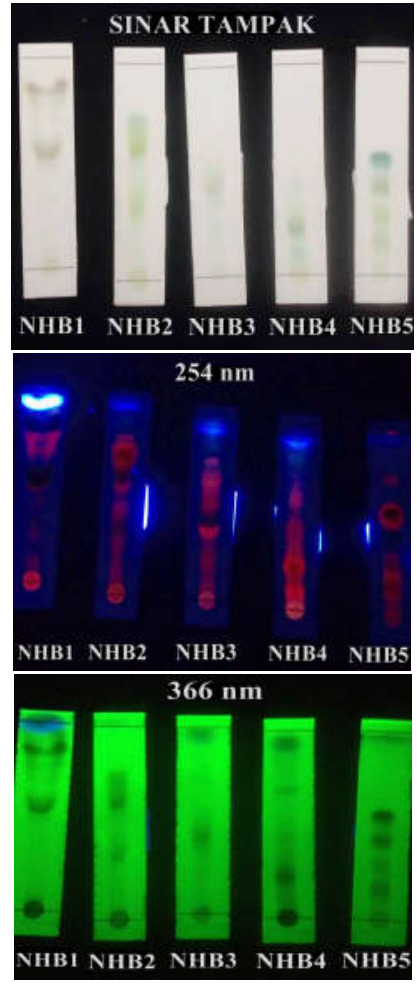

(1) lanjutan. Eluen yang digunakan antara lain $n$-heksana:etil asetat $(8: 2)$ dan $(7: 3)$. NHB terpisah menjadi 5 fraksi yaitu NHB1; NHB2; NHB3; NHB4; NHB5 sedangkan untuk fraksi NHC terpisah menjadi 5 fraksi yaitu NHC1; NHC2; NHC3; NHC4; NHC5.

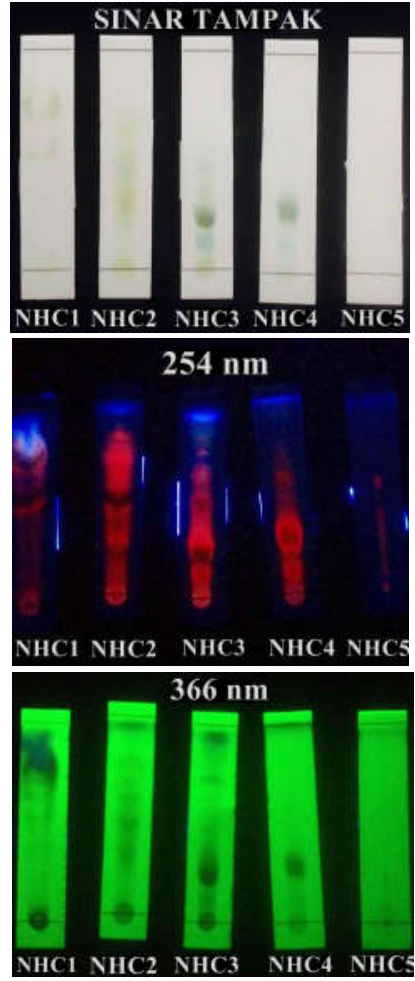

(2)

Gambar 3. Hasil KLT fraksi (1) NHB dan (2) NHC dengan eluen $n$-heksana:etil asetat (8:2) diamati pada sinar tampak, sinar UV $254 \mathrm{~nm}$, dan 366nm 
Seluruh proses pemisahan baik metode kromatografi kolom cair vakum (KCV) dan kromatografi kolom konvensional (KK) menggunakan KLT dengan eluen $n$ heksana:etil asetat (8:2) untuk memperoleh pemisahan terbaik. Fraksi-fraksi yang terpisah seluruhnya dilakukan uji aktivitas antioksidan dan antibakteri. Hasil pengujian aktivitas antioksidan dan antibakteri fraksi-fraksi tersebut dapat dilihat pada Tabel 1 dan Gambar 4.

Tabel 1. Hasil pengujian aktivitas antioksidan dan antibakteri fraksi $n$-heksana

\begin{tabular}{cccc}
\hline \multirow{2}{*}{ Fraksi } & $\begin{array}{c}\text { Aktivitas } \\
\text { Antioksidan }\end{array}$ & \multicolumn{2}{c}{ Aktivitas Antibakteri } \\
\cline { 3 - 4 } NHB1 & + & S. aureus & E. coli \\
NHB2 & - & - & + \\
NHB3 & + & - & - \\
NHB4 & + & - & - \\
NHB5 & - & - & - \\
NHC1 & + & + & - \\
NHC2 & - & + & - \\
NHC3 & + & + & - \\
NHC4 & - & - & - \\
NHC5 & - & - & -
\end{tabular}

Keterangan tabel: + : terdapat aktivitas dan : tidak terdapat aktivitas

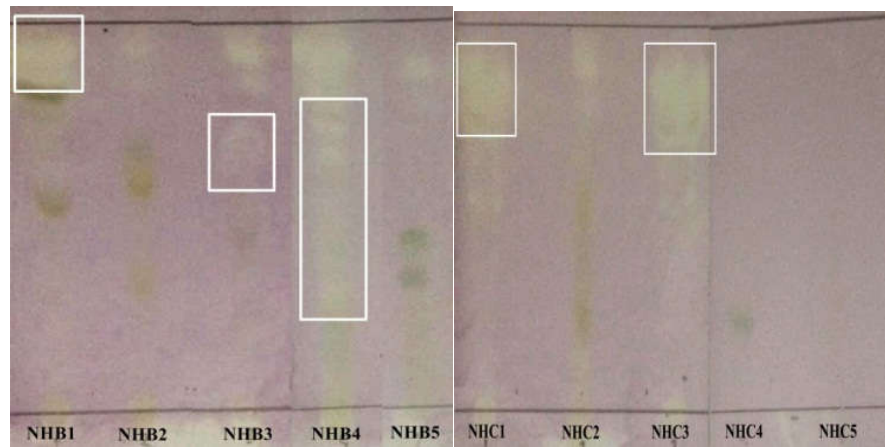

Gambar 4. Pengujian aktivitas antioksidan pada plat KLT fraksi n-heksana. Garis putih menunjukkan perubahan warna DPPH yang disemprotkan dari ungu menjadi kuning pucat yang berarti bahwa fraksi n-heksana memiliki aktivitas antioksidan.
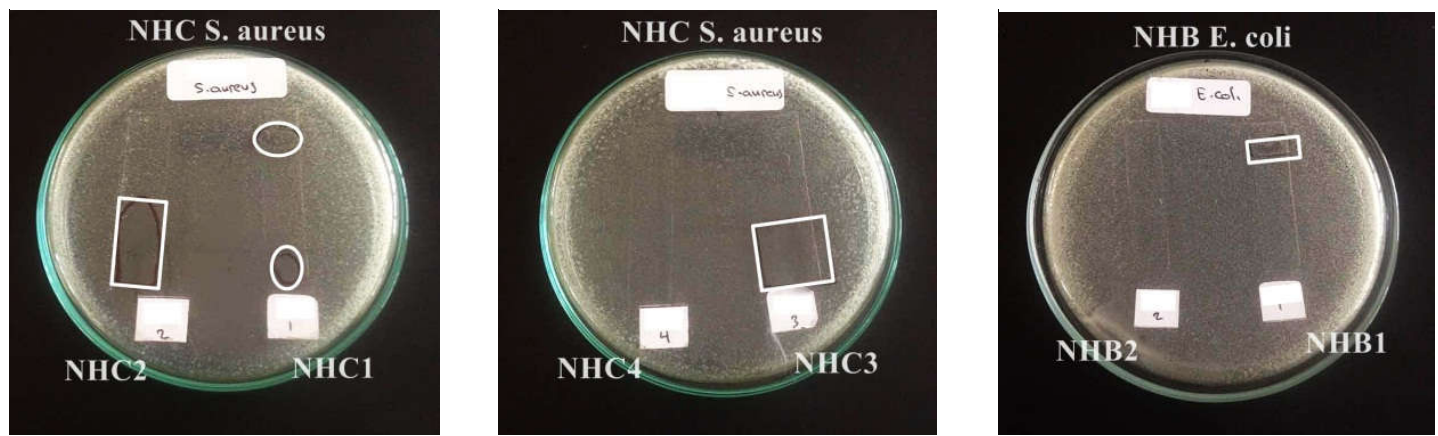

Gambar 5. Hasil positif pengujian aktivitas antibakteri fraksi $n$-heksana yang ditunjukkan garis putih yang menampakkan adanya zona bening/ hambat pada medium agar. 
Berdasarkan Gambar 4, 5 dan Tabel 1 terlihat bahwa terdapat 5 fraksi $n$-heksana yang memiliki aktivitas antioksidan yaitu NHB1, NHB3, NHB4, NHC1, NHC3 sedangkan fraksi yang memiliki aktivitas antibakteri yaitu NHB1, NHC1, NHC2, NHC3. Terdapat 2 fraksi yang memiliki baik aktivitas antioksidan maupun antibakteri yaitu NHC1 dan NHC3. Hasil positif antioksidan disebabkan oleh kemampuan senyawa antioksidan pada fraksi yang dapat memucatkan warna DPPH. DPPH (2,2 Diphenyl-1picrylhidrazyl) merupakan radikal bebas yang tidak stabil karena terdapat elektron yang tidak berpasangan, dalam larutan metanol akan berwarna ungu. Pemucatan larutan DPPH mencerminkan jumlah elektron yang ditangkap oleh radikal DPPH sehingga mencerminkan juga aktivitas sampel yang akan diteliti [5].

Pengujian aktivitas antibakteri digunakan 2 bakteri uji yaitu $S$. aureus sebagai bakteri gram positif dan E.coli sebagai bakteri gram negatif. Terlihat dari
Tabel 1 bahwa tidak ada fraksi yang memiliki aktivitas antibakteri pada kedua bakteri uji. NHB1 memiliki aktivitas antibakteri pada bakteri E. coli. NHC1, NHC2 dan NHC3 memiliki aktivitas antibakteri terhadap bakteri $S$. aureus. Aktivitas antibakteri terlihat terlihat dari adanya zona bening. Zona bening yang terbentuk yaitu akibat dari senyawa antibakteri pada fraksi yang meresap ke permukaan medium. Zona bening menandakan tidak terjadi pertumbuhan bakteri. Baik pengujian aktivitas antioksidan maupun antibakteri pada penelitian ini merupakan pengujian secara kualitatif.

Pengujian kandungan metabolit sekunder dilakukan dengan tujuan mengetahui kemungkinan golongan metabolit sekunder yang memiliki aktivitas antioksidan dan antibakteri. Kandungan metabolit sekunder yang terdapat pada fraksi aktif antioksidan dan antibakteri dapat dilihat pada Tabel 2 .

Tabel 2. Hasil pengujian metabolit sekunder fraksi aktif antioksidan dan antibakteri fraksi $n$-heksana

\begin{tabular}{ccccccc}
\hline \multirow{2}{*}{ Fraksi } & \multicolumn{5}{c}{ Metabolit Sekunder } \\
\cline { 2 - 6 } & Alkaloid & Flavonoid & Steroid/terpenoid & Fenol & Saponin \\
\hline NHB1 & + & - & + & - & - \\
NHB3 & + & - & - & - & - \\
NHB4 & + & - & - & - & - \\
NHC1 & + & + & - & - & - \\
NHC2 & - & - & - & - & - \\
NHC3 & - & - & - & - & - \\
\hline gan tabel: & + t: teridentifikasi metabolit sekunder dan - : tidak teridentifikasi metabolit sekunder
\end{tabular}

Berdasarkan hasil pengujian metabolit sekunder terlihat bahwa NHB1 positif mengandung alkaloid dan steroid/terpenoid, NHB3 dan NHB4 mengandung alkaloid, NHC1 mengandung alkaloid dan flavonoid. Sedangkan NHC2 dan NHC3 tidak mengandung baik alkaloid, flavonoid, steroid/terpenoid, fenol maupun saponin. Kandungan flavonoid dapat mengindikasikan adanya senyawa yang mampu bersifat sebagai antioksidan dan antibakteri. Menurut Sarker ${ }^{[6]}$, kebanyakan flavanoid merupakan senyawa antioksidan yang potensial. Begitu pula alkaloid dan terpenoid, terpenoid terbukti mempunyai potensi aktivitas antioksidan 
dan efek yang protektif melawan oksidatif stress di dalam mitokondria terutama terpenoid lipofilik. Alkaloid juga memiliki aktivitas antioksidan yang dapat bertindak sebagai peredam hidroksi radikal [7].

\section{KESIMPULAN}

Berdasarkan hasil penelitian diketahui profil kromatografi senyawa antioksidan dan antibakteri fraksi $n$ heksana daun Libo (Ficus variegata Blume.) untuk memisahkan senyawa aktif antioksidan dan antibakteri diperoleh melalui 2 metode pemisahan yaitu kromatografi kolom cair vakum $(\mathrm{KCV})$ dan kromatografi kolom konvensional (KK). Eluen yang digunakan untuk menghasilkan pemisahan terbaik yaitu $n$-heksana:etil asetat dengan perbandingan 8:2. Fraksi $n$ heksana daun Libo memiliki aktivitas antioksidan dan antibakteri. Metabolit sekunder yang terkandung di dalam fraksi aktif tersebut antara lain alkaloid, flavonoid, steroid/terpenoid.

\section{DAFTAR PUSTAKA}

1. Windono, T., Soediman, S., Yudawati, U., Ermawati, E., Srielita, Erowati, T. I. Uji Peredam Radikal Bebas terhadap 1,1-Diphenyl-2-Picrylhydrazyl (DPPH) dari Ekstrak Kulit Buah dan Biji Anggur (Vitis vinifera L.) Probolinggo Biru dan Bali. 2001. Artocarpus. 1, 34-43
2. Ong, N.O.Chia, S.E..2001. Oxidatve Damage Antioxidant and Human Sperm. In Nasretman and Packer, Micronutrients and Healt; Molecular, Biological Mechanism, Illionis, AOCS Pers.

3. Greenwood, Norman N. And A. Earnshaw. 1997. Chemistry of the Elements 2nd Edition. Oxford: Butterworth - Heinemann

4. Rijai, Laode. 2013. Potensi Tumbuhan Libo (Ficus variegata Blume) Sebagai Sumber Bahan Farmasi Potensial. J. Trop. Pharm. Chem. 2. (3). 166-179.

5. Marliana, E., 2007, Analisis Senyawa Metabolit Sekunder dari Batang Spatholobus ferrugineus (Zoll \& Moritzi) Benth yang Berfungsi sebagai Antioksidan, Jurnal Penelitian MIPA, 1, (1), 23-29.

6. Sarker, S. D. dan Lutfun N. 2009. Kimia Untuk Mahasiswa Farmasi, Bahan Kimia Organik, Alam dan Umum. Pustaka Pelajar: Yogyakarta.

7. Haraguchi, H. (2001). Antioxidative Plant Constituents. In Bioactive compounds from natural sources, first published. New York: Taylor and Francis Inc. pp. 338-377. 